\title{
Marie de Flavigny, comtesse d'Agoult, Correspondence générale, t. I-II-III
}

\section{Lise Sabourin}

\section{(2) OpenEdition}

1 Journals

\section{Édition électronique}

URL : https://journals.openedition.org/studifrancesi/46120

DOI : 10.4000/studifrancesi.46120

ISSN : 2427-5856

Éditeur

Rosenberg \& Sellier

\section{Édition imprimée}

Date de publication : 1 octobre 2007

Pagination : 468

ISSN : 0039-2944

\section{Référence électronique}

Lise Sabourin, « Marie de Flavigny, comtesse d'Agoult, Correspondence générale, t. I-II-III », Studi Francesi [En ligne], 152 (LI | II) | 2007, mis en ligne le 30 novembre 2015, consulté le 24 novembre 2021. URL : http://journals.openedition.org/studifrancesi/46120 ; DOI : https://doi.org/10.4000/ studifrancesi.46120

Ce document a été généré automatiquement le 24 novembre 2021.

\section{(c) 9 (i) $\Theta$}

Studi Francesi è distribuita con Licenza Creative Commons Attribuzione - Non commerciale - Non opere derivate 4.0 Internazionale. 


\title{
Marie de Flavigny, comtesse d'Agoult, Correspondence générale, $t$. I-II-III
}

\author{
Lise Sabourin
}

\section{RÉFÉRENCE}

MARIE DE FLAVIGNY, comtesse d'AGOULT, Correspondence générale, édition établie et annotée par Charles F. DUPECHEZ, Paris, Honoré Champion, t. I: 1821-1836, 2003, pp. 571; t. II: 1837-octobre 1839, 2004, pp. 611; t. III: novembre 1839-1841, 2005, pp. 677.

1 Muni en chaque volume d'une chronologie annuelle et de riches index (de ses correspondants, des diminutifs et prénoms employés dans les missives, de tous les noms propres cités), cette publication de la correspondance croisée de Marie d'Agoult offre l'heureux panorama de ses nombreuses relations d'élite, tant de naissance que d'esprit et de créativité artistique. Chaque lettre est munie de ses origines autographes et de l'indication de ses publications antérieures, mais sans annotation critique. Les annexes apportent en outre les précieux agendas de 1835 et 1836, le journal de 1837-39 (complété et corrigé par rapport à l'édition des Mémoires, souvenirs et journaux due à ce même éditeur, Mercure de France, 1990), les envois de livres reçus, les notes de lecture échangées avec l'abbé Gerbet, des documents iconographiques et biographiques.

2 Le cas de Liszt a posé problème à l'éditeur, dans la mesure où sa correspondance avec Marie a déjà été publiée (les résumés des lettres de Franz renvoient donc à l'édition de Serge Gut et Jacqueline Bellas, Fayard, 2001), mais Charles Dupêchez n'a pas voulu priver cette correspondance générale de ses lettres reçues de Marie, aux côtés de celles de son frère Maurice et de sa femme. De plus, il ne pouvait omettre des missives sources de bien des articles de la Revue et Gazette musicale de France ou du vécu originel de l'écriture à quatre mains des Lettres d'un bachelier. Signalons aussi la mise au point apportée par cette correspondance élargie aux proches à propos des conditions du 
départ pour rejoindre Liszt. L'idée reçue d'un enlèvement apparaît largement démentie par son profond désir de rompre avec son milieu, après la mort de sa fille aînée Louise. La première de ses autres maternités lui apparait bien comme l'aurore d'une nouvelle vie à mener pour cette «femme de trente ans», malgré l'oppression de culpabilité que saura lui infliger ensuite son entourage familial, soucieux d'étouffer un scandale moins exceptionnel qu'on ne l'a dit.

Souhaitons que cette publication incite certains héritiers des correspondants de la comtesse d'Agoult à exhumer les lettres qu'en ont reçues leurs ancêtres, afin d'enrichir encore une correspondance générale qui présente quelquefois, surtout pendant sa jeunesse, plus de lettres de ses destinataires que des siennes. En attendant peut-être ces compléments, le lecteur retiendra les facettes marquantes de cette femme éminente, après Mme de Staël et parallèlement à George Sand. Son amitié avec cette dernière, avant l'incidence des amours avec Chopin, est vécue dès son brillant salon de la rue de Beaune, puis à Nohant avant de gagner l'Italie. D'autres amis, retrouvés ou nouveaux, tels Vigny, Balzac, Hugo, Ingres, Sainte-Beuve, Mickiewicz, Hortense Allart et Henri Lehmann, marqueront, au retour parisien, rue Neuve-des Mathurins, celle qui est devenue par son talent l'écrivain Daniel Stern, à qui Girardin offre les colonnes de son journal. Le naufrage d'un mariage trop désassorti trouve quelque compensation dans l'éducation attentive de ses filles à Croissy, mais plus tard les bonheurs et tourments des conséquences de sa passion pour le musicien de génie la priveront de vraiment s'occuper de Blandine et Cosima, pourtant futures Mmes Émile Ollivier et Richard Wagner, faute de pouvoir réparer l'abandon de Claire et de Daniel. Restent pour notre plaisir de lecteurs le témoignage pénétrant et magnifique de cette voyageuse inlassable et curieuse, de cette intellectuelle indépendante dans un temps qui lui accorde peu ce rôle, sauf durant l'enchantement de l'Italie où s'épanouit librement son amour en communion avec une plèiade d'artistes - Rossini, Spontini, Hiller, Mercadante, Perucchini, Schnetz, Ingres, Bartolini, Putinatti, Lemoyne... - et d'aristocrates collectionneurs esthètes - les Neipperg, Di Negro, Sagredo, Mulazzani, Boccella. C'est dire tout l'intérêt de ce beau travail éditorial qui nous donne à vivre l'entrecroisement de multiples figures importantes du xix ${ }^{e}$ siècle. 